\title{
Teaching
Anthropology
}

2022, Vol. 11, No. 2, pp. 37- 47.

\section{Toward a Pedagogy for Consumer Anthropology: Method, Theory, Marketing}

\author{
Robert J. Morais \\ Columbia Business School, USA
}

\begin{abstract}
This paper focuses on teaching the application of anthropology in business to marketing students. It begins with the premise that consumer marketers have long used ethnography as a component of their qualitative market research toolkit to inform their knowledge about and empathy for consumers. A question for market research educators who include ethnography in their curricula is if and how to teach the richness of anthropologically based approaches, especially given a decoupling of ethnographic method from anthropological theory in much consumer research practice. This discussion might also resonate with anthropology educators who are interested in the ways anthropology is applied in commercial settings. As a demonstration of a teaching mode rather than a research report, this paper describes how a consumer anthropology market research project is used experientially in the classroom to help marketing students learn and appreciate the application of both anthropological method and theory for brand-building. Included is a summary of an ethnographic project on Duncan Hines cake mix and an in-class student exercise during which three conceptual 'jumping off points from anthropological theory were used to generate marketing initiatives.
\end{abstract}

Keywords: Consumer Anthropology; Market Research; Anthropological Method and Theory; Ethnography

\section{Introduction}

Consumer marketing initiatives can be developed without a market research foundation, but a brand is well served by research conducted among its target audiences. Marketers base their intelligence about consumers on multiple sources, e.g., secondary data produced by governments or open access research and proprietary studies such as surveys, text mining, focus groups, in-depth one-on-one interviews, and ethnographies. Ethnography is used to enhance marketers' knowledge about and increase their empathy for consumers. ${ }^{1}$ Consumer anthropology, the market research application of anthropological theories and methods including but not limited to ethnography, has also contributed to strategic planning, product innovation, and creative development (Arnould and Wallendorf, 1994; Malefyt and Morais, 2012; McCabe and Denny, 2019; Sunderland and Denny, 2007). A question for market research educators who include ethnography in their curricula is if and how to teach the richness of anthropologically based approaches, especially given a decoupling of ethnographic method from anthropological theory in much consumer research practice. ${ }^{2}$ This discussion might also resonate with anthropology educators who are interested in the ways anthropology is applied in commercial settings. As a demonstration of a teaching mode rather than a research report, this paper describes how a real-world consumer anthropology research project was used experientially in the classroom to help marketing students learn and appreciate the application of both anthropological method and theory for brand-building.

\section{Business Education, Ethnography, and Anthropology}

Ethnography is taught in business schools as a component of the qualitative market research toolkit along with focus groups and in-depth interviews. It is not typically augmented with cultural anthropology theory (Gebhardt, 2015; Malhortra and Dash, 2017: 212; cf. Baba, 2014; Stewart, 2014; Sunderland, 2013). Cultural anthropology is more fully represented in business schools and related teaching settings when qualitative market research is taught by anthropologists (see https://www.businessanthro.com/teaching; https://www.epicpeople.org/usingtheory-in-research/; cf. Tian and Walle, 2008; Krawinkler, 2016). The appeal of ethnography to marketers, marketing professors, and marketing students is likely driven by its intrinsic attributes versus surveys and focus groups. Through close naturalistic observation, conversational interviewing, and thoughtful interpretation, ethnography can expand a marketer's understanding of consumer behaviour, attitudes, and motivations, producing "thick data" and deep insights (Hasbrouck, 2018; Moisander et al., 2020). The benefits of anthropological theory for consumer research are less apparent to most business executives, business professors, 
and business students. Concepts such as holism, ritual, liminality, symbolism, reciprocity and, more broadly, the concept of culture, and the ways they produce and reflect meaning in the lives of consumers, are fruitful analytical frameworks, but they require more explanation to grasp and apply in business (cf. Tett, 2021). In addition, marketing managers tend to focus more on psychological queries surrounding consumer attitudes and behaviour than cultural analysis (Sunderland and Denny, 2003; Morais and Malefyt, 2010). Conducting bona fide ethnography is not easy but tapping anthropological ideas for insights concerning human actions, cognition, and sentiments can be hard, at least for marketing students not inclined toward theoretical constructs. ${ }^{3}$ The emphasis on method over theory in market research courses might trace to the nature of market research education. ${ }^{4}$ It is more pragmatic than theoretical, with MBA (Master of Business Administration) programs in particular serving as a simulacrum for business experiences through case study analysis, team exercises, and networking as preparation for business careers (Orta, 2019).

Over the past several decades, consumer anthropologists have participated increasingly in the production of knowledge to inform marketing initiatives. (Hasbrouck, 2018; Malefyt, 2015; Malefyt and Morais, 2012; McCracken, 2016; Morais, 2014; Morais, 2020; Maschio, 2015; McCabe, 2014; McCabe and Denny, 2019; McCabe et al., 2017; Sunderland and Denny, 2007). In many of these instances, anthropologists have conducted research that yielded a single marketing insight; Morais (2014) documents how a consumer research study can produce several strategic and tactical directions. As a supplement to research projects, marketers sometimes convene workshops that use research findings as a springboard for "brainstorming" or ideation (Osborn, 1957; for a more recent approach, see Boyd and Goldenberg, 2013). In those sessions, executives generate a multitude of marketing ideas that will be winnowed down to a manageable number for assessment among target consumers before being launched into the marketplace. These workshops focus on product innovation, brand positioning, marketing tactics, or any number of topics decided upon by a marketing team. They also provide an opportunity for organizational team building (Malefyt, 2003).

\section{A Consumer Anthropology Class Experience}

Students in three business school marketing classes ${ }^{5}$ were given a definition of consumer anthropology, presented with a summary of an ethnographic project on the Duncan Hines packaged cake mix brand and a related workshop, and then engaged in a class exercise using anthropological concepts to spark marketing ideas. ${ }^{6}$ The desired learning outcomes were to impress upon students via a business case how marketers' consumer understanding could benefit by incorporating both ethnographic method and anthropological theory and to enable students to experience first-hand the application of this approach. For in-class pedagogical purposes, the Duncan Hines research findings and workshop content were edited.?

When teaching consumer anthropology to business students, it is constructive to distinguish between the method of ethnography and the broader discipline of cultural anthropology as it is applied in business, with special attention to cultural anthropology's theoretical contributions. After describing ethnography as a methodology for naturalistic observation, semi- and unstructured interviewing, and thoughtful analysis, cultural anthropology can be characterized as a way to turbocharge ethnographic findings. Stated differently, cultural anthropology contributes a mode (borrowing from archaeology) for digging deeper and thinking deeper. ${ }^{8}$ The goal is to progress beyond basic research findings to profound insights that can stimulate novel strategic and tactical planning for marketing initiatives. Figure 1 illustrates representative conceptual domains from cultural anthropology that can be applied in market research. 
Figure 1: Examples of Anthropological Theoretical Concepts Presented in Class ${ }^{9}$

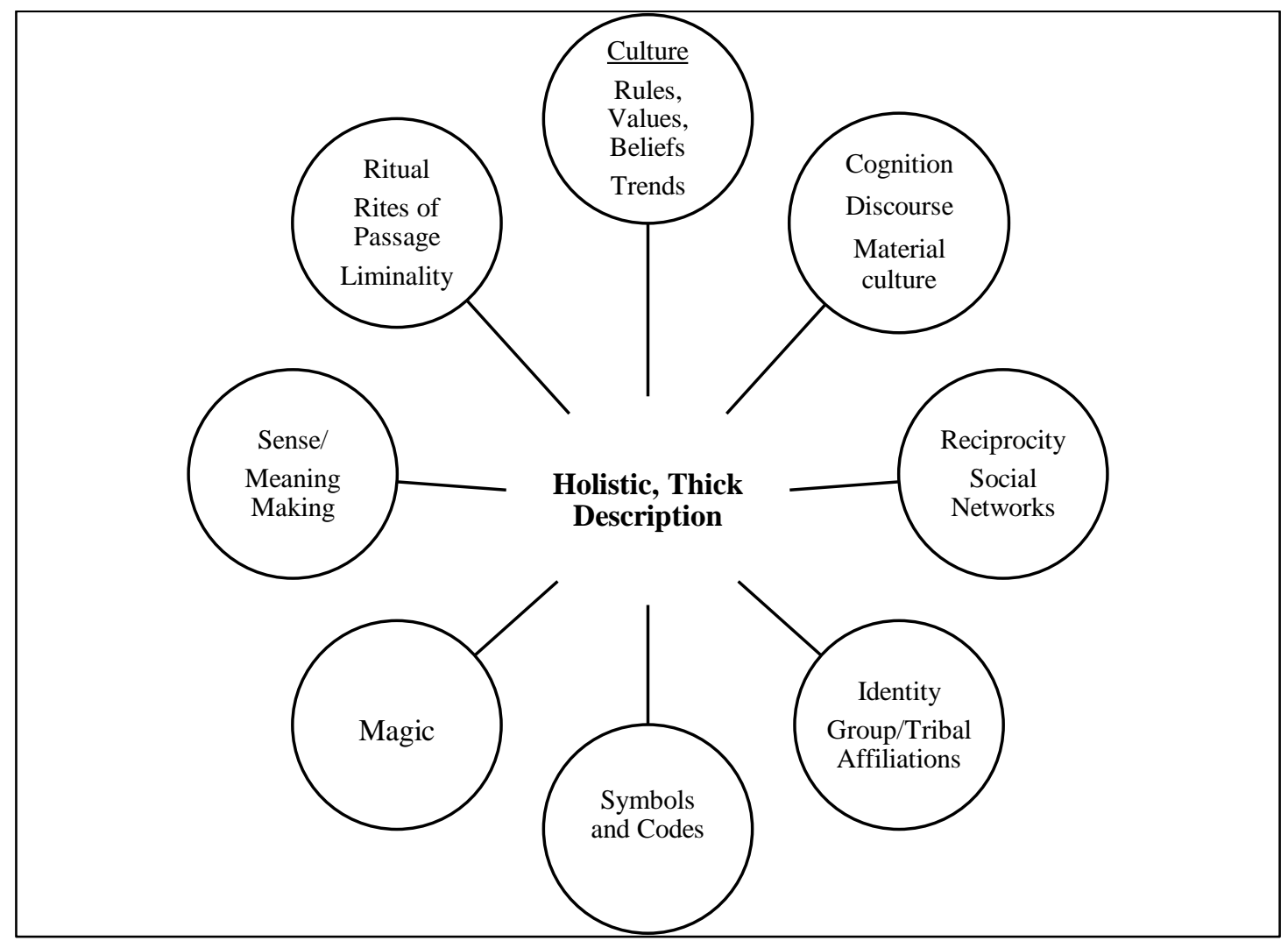

Given that ethnography is often separated from or conflated with cultural anthropology in market research, distinguishing basic ethnographic learning from anthropologically informed insights by using concrete examples can telegraph the contrast to market research students (Table 1).

Table 1: Consumer Ethnography and Consumer Anthropology ${ }^{10}$

\begin{tabular}{|l|l|}
\hline \multicolumn{1}{|c|}{ Ethnographic Observation } & \multicolumn{1}{c|}{ Anthropological Insight } \\
\hline The experience of driving a car & A car as a culture-based symbol of achievement \\
\hline Bicycle care as behavior, thoughts, feelings & Bicycle care as a metaphor for one's body \\
\hline Buying and applying make-up & Make-up as identity \\
\hline Dog food as a way of showing love & Dog food as cognitive classification \\
\hline Hotel service as good or bad & Hotel service as symbolic interaction \\
\hline House cleaning as a series of actions & House cleaning as a rite of passage \\
\hline How customers experience a pizza parlor & Pizza parlor as a service performance space \\
\hline
\end{tabular}

\section{The Duncan Hines Project}

The Duncan Hines insights group was interested in better understanding a consumer segment, which they termed the "passionate baker." At the inception of the project, the Duncan Hines team shared their project objectives with the market research firm:

- Characterize the passionate baker and what her life is all about

- Define the role baking plays in her life

- Understand her baking process from inspiration through planning, preparation, in-store purchases, the baking itself, and the end result (customer journey mapping)

- Define brand and category perceptions

- Devise ways to grow the Duncan Hines brand 
The research firm was asked to design an ethnographic research plan. ${ }^{11}$ The budget allowed for eight respondents, two respondents per day, for a three-hour ethnographic encounter with each respondent. The protocol entailed home visits and in-store "shop-alongs." After the research proposal was submitted, the justification for ethnographies given their high cost compared with focus groups was questioned by the senior vice president of marketing. A meeting was held during which the research firm explained the merits of anthropologically informed ethnography and invited the senior vice president to witness some of the ethnographies first-hand. He approved the project and joined the team for one home visit. In advance of the fieldwork, the research firm led a preparation session for the Duncan Hines marketing and insight groups to ensure appropriate behaviour during the ethnographies. As the fieldwork approached, a Duncan Hines insight manager asked the research firm to conduct a face-to-face meeting during which the research report would be presented, and the firm would facilitate a market idea generating workshop. Fieldwork was executed in Northern New Jersey, USA within driving distance of the Duncan Hines headquarters to enable on-site participation of a rotating group of Duncan Hines executives and their consultants.

\section{Respondent Profile}

All of the respondents were women. In each of the market research classes, a student questioned why only women were recruited for this research. The reason: Duncan Hines quantitative data showed that women are the primary purchasers and users of packaged baked goods. Half of the respondents were age 25-44; half were age 45-64. All of them were classified as passionate bakers and considered themselves creative, imaginative, or artistic based upon attitudinal questions in the recruitment screener. Most of the women were married with children; some had grandchildren. They had purchased and used a boxed cake mix at least twice in the past three months; some of the respondents were both boxed and scratch bakers.

\section{Before the Fieldwork}

In advance of the ethnographies, the respondents were told about topics the ethnographic team would discuss (generally and with no reference to Duncan Hines) and were asked to plan on baking during the in-home visit. They were instructed to have the ingredients they needed to bake on hand. The shop-alongs followed the initial home visit to allow for the respondents to purchase items needed for baking that they did not have on hand (despite prior instructions). Before the arrival of the research team, the respondents were asked to create collages that illustrated the people, things, activities, and values that are currently most important in their lives and those they envision being most important five and ten years in the future.

\section{Ethnographic Fieldwork}

The home visits began with a room-by-room house tour and an informal discussion punctuated with storytelling about the respondents' families and social lives. The team then moved into the living room or other family space to review the respondents' collages. Discussion continued in the kitchen and focused on cooking, baking, shopping, and eating baked goods. Although the Duncan Hines marketing and insight executives were most interested in the bakers' psychology, the research firm also incorporated anthropological perspectives that could frame consumer engagement with baking holistically in the bakers' lives. For that reason, both psychological and anthropological interviewing techniques were incorporated. (see Sunderland and Denny, 2003; Morais and Malefyt, 2010; Morais, 2020, on this issue). The semi-structured interviewing began with purposeful naivety, a technique where the interviewer asks fundamental questions that can reduce researcher bias and assumptions that impede fresh insights, e.g., What is cooking? What is baking? How are the two similar and how are they different? How are baking from a box and from scratch similar and how are they different? Mapping the bakers' journeys involved elicitation of thoughts and events that triggered baking, how they planned their baking, how they arrived at recipe choices, where and how they shopped for ingredients, the baking itself, and sharing of the baked item. An anthropological perspective on journey mapping entails viewing each journey phase as a passage with a beginning, middle, and end with psychological and cultural components. A key question for the research firm was how baking transforms the baker and her social relationships. The respondents were asked to tell stories about past baking on their own, with others, and by others to discover emotional and social attendants. In that context, the research team was particularly attuned to stories that unveiled baking as a gift with interpersonal meaning. The research team also aimed to discover, mainly through storytelling, how baking expresses beliefs and values. After spending about 90 minutes in the respondents' homes, the team accompanied them to the grocery store in which they usually shopped for boxed baked goods. The team observed shopping choices closely and inquired about the reasons for those choices. The objective was to learn on site which factors are most influential in determining the purchase of particular baking product(s) and brands, e.g., shopping list, family member's request, brand preference, size, ease/difficulty of baking instructions, price/coupons/promotions, ingredients, etc. along with the shoppers' in-store navigation. The research team 
made note of the brands and product SKUs (stock keeping units) the respondents looked at, picked up and studied more carefully, placed back on the shelf, and bought. The store visit lasted about 30 minutes. The ethnography team and the respondents returned to the respondents' homes for the remainder of the ethnographic encounter. They were observed baking with Duncan Hines while they narrated the process. Discussion centred on what they were doing and how they felt about each stage of the baking activity. If the item could be fully baked and consumed while the research team was present at the respondent's home, the team would taste it and talk with the baker about the end result.

\section{Major Findings}

Home baking is expressive and instrumental, and the balance between the emotional and functional components of the process is not easily quantifiable. An emotionally resonant phase of the baking journey is the search for and selection of the most appealing item to bake. For some bakers, it is a joyful sequence of exploration and discovery. One woman showed an old, tattered recipe book in which her now deceased father had written, "Duncan Hines"; the moment produced a flood of warm emotions associated with her father. When shopping for packaged cake mixes, specific brands are less important than the variety desired, e.g., form or flavour. The ease of preparation directions is a crucial factor; the simpler the better, as long as the baker feels she is doing more than buying a finished product. Price is not a major driver of brand choice, functioning as a tiebreaker. Respondents felt that the packaged cake mix aisle could be easier to navigate and that the package designations, especially the directions, are not always clear.

When asked to define what baking is, respondents described it primarily in emotional terms, i.e., as therapy, nurturing, a time of excited anticipation, and a process that creates and rekindles memories. Baking is fun, not work. As one woman said when contrasting baking with cooking, "Baking is something you do because you want to do it." Another woman commented that when baking, "I feel happy, silly, and carefree." One respondent said, "Baking equates to happiness." The process of baking often entails a sense of "being in a zone," essentially having a flow experience (Csikszentmihalyi, 1990). Baking with others can engender intimate conversations that might otherwise be difficult. A mother mentioned that when she is baking with her teenage daughter, the daughter opens up about her personal relationships. In this instance, baking transformed the kitchen into a safe place for communication and family bonding. Baking represents, transmits, and reinforces values in bakers' lives. Parents of young children often want to involve them in the choice of a specific baked good option, the baking activity, and the sharing of the finished product with others. One mother recounted how during baking her children learn they can follow rules and add their own creative touches. A woman with no children at home brought baked items into her office to enhance personal connections with her co-workers. Baking offers an opportunity, as one respondent put it, to "give away something of myself" to family and social network. A boxed baking good such as Duncan Hines, with its foolproof steps, bolsters the baker's confidence that she will produce the basic item flawlessly and, if she chooses, be able to add personal flourishes such as fruit or special frosting. Respondents' mastery of baking and their identity as "a baker" carries high personal satisfaction.

\section{Research Synthesis and Workshop}

The research findings addressed the Duncan Hines' need to learn about the role baking plays in the passionate baker's life and the details of her baking journey. Another project goal was to mine the research findings to create ways to grow the Duncan Hines brand. The workshop that followed the research presentation was designed for that purpose. At the beginning of the presentation, the research firm instructed the audience to attend closely to the findings as a foundation for the workshop that would follow. At the close of the presentation, the firm presented several conceptual territories to further stimulate ideation. These areas were based upon the research findings and related insights, some of which reflected an anthropological sensibility. Example \#1: Duncan Hines as a way to advance bakers' personal and culture-based values regarding family, the interplay of rules and creativity, and gifting, along with their desire to transmit those values to their children. Example \#2: Duncan Hines as a catalyst for the kitchen as a special, transformative place where, to cite one evocative story, baking with Duncan Hines can facilitate intimate, otherwise hard to have conversations with loved ones.

When the workshop began, the Duncan Hines marketing and insight executives, their consultants, and their advertising partners were charged with devising ways to grow the Duncan Hines brand based upon the research. Small teams were formed and instructed to "speed date" with ideas from other teams, improve them, and then move on to the next idea. The participants were asked to consider: How can an idea become stronger and more competitive? What can Duncan Hines as a brand own about it? The ideas were voted upon by the assembled group. The plan going forward was for the top contenders to be refined prior to consumer exposure. One 
example of a team's thinking: Beginning with the finding that baking with Duncan Hines can be a memory maker, poignant stories from consumers about favourite Duncan Hines baking experiences could be posted on the brand's web site.

\section{The Student Exercise}

After the summary of the Duncan Hines project, students were given directions to use one or more of three conceptual jumping off points for marketing idea generation: gift giving; modelling cultural rules; place (Figure 2). As depicted in Figure 1, there is a surfeit of anthropological concepts that could open new vistas for marketing initiatives. The three domains selected were judged by the professor to be manageable for the students during the class session, vivid milieus for consumer meaning making, and fertile springboards for brand marketing initiatives. Anthropological and related theory was not described in detail. The students were shown the illustrations in Figure 2 and presented with theory verbally as summarized in the three sections that follow. The aim was to introduce them to how marketing possibilities could be inspired by anthropology rather than educate them fully on anthropological theory. References were made available to students who wished to learn more about the three conceptual domains or consumer anthropology overall. During this portion of the class, students were engaged, but only a few expressed a strong interest in the theoretical frameworks. Perhaps that is a function of the practical mindset of business school students.

Figure 2: Anthropological Theory Domains as Jumping Off Points

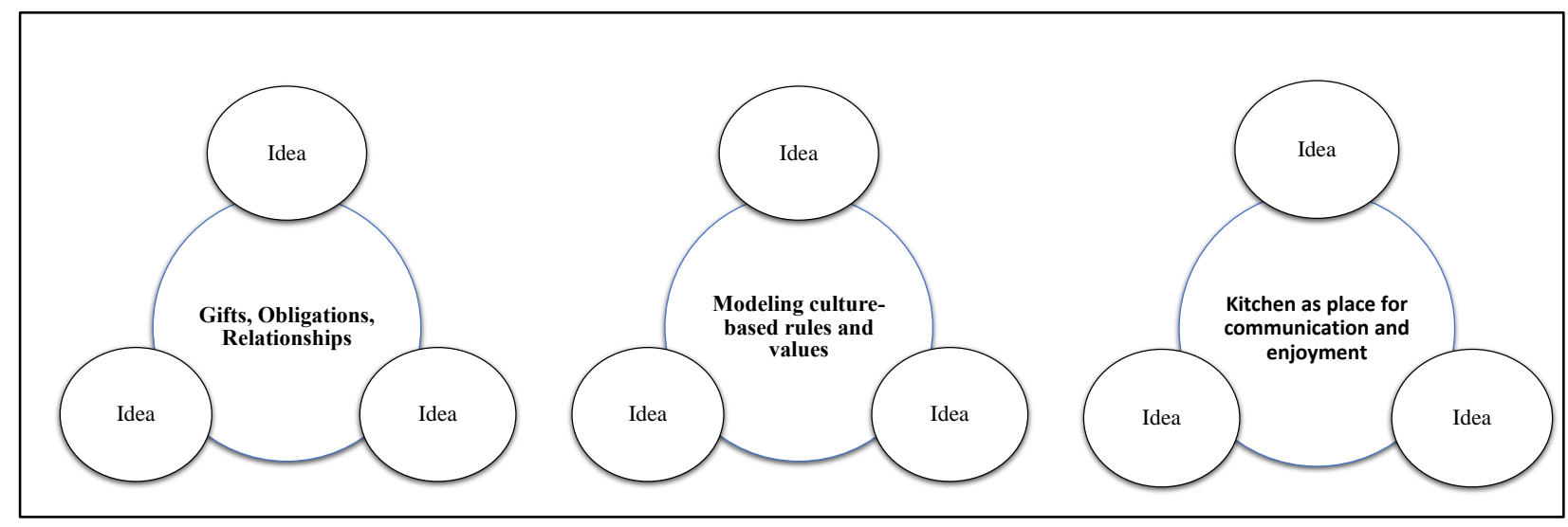

\section{Brand as Social Connector}

Movement from a finding to an insight can be informed by anthropological ideas surrounding gifts, e.g., manifest and implied obligations, the formation of relationships, and different types of reciprocity (Mauss, 1990; org 1925; Sahlins, 1972). The process of gift giving and gift exchange based on Sherry's (1983) model could be fodder for ideation. Additional theory from sociology can be incorporated. For example, Granovetter (1973) originated the phrase, "The Strength of Weak Ties" in the context of network analysis. For the woman who brought baked goods into her office, it was apparent during the ethnographic interview that the gift added emotional resonance to her weak office ties. Giving a baked item as a gift is often a form of generalized reciprocity that forges long term bonds between the baker and the recipients of the baked good that she produces. Duncan Hines could be a conduit for this process.

\section{Brand as Cultural Transmitter}

Growing up and learning the behavioural rules of a culture can evoke stress and anxiety for children and their parents. Roberts et al. (1962) noted, "there is an overall process of cultural patterning whereby society induces conflict in children through its child-training processes; that society seeks through appropriate arrays...to provide an assuagement of these conflicts... and society tries to provide a form of buffered learning through which the child can make enculturative step-by-step progress toward adult behavior" (Roberts et al., 1962: 184-185). Along these lines, recall the mother who described how she used Duncan Hines as a simple and fun way to teach her young children how to follow directions - instructions on the Duncan Hines package - and be creative by adding their own customized baking decorations. Following the "conflict-enculturation theory of model involvement" proposed by Roberts and his associates, this mother combined rules for a baking recipe with creativity, transmitting culturally desired values and skills in a low stress context. Duncan Hines could participate in this kind of "buffered learning" experience. 


\section{Brand as Creator of a Special Place}

Physical spaces that humans inhabit are central to cultural anthropology as functional and symbolic locales (see Aucoln, 2017, for an anthropological review). The places we occupy not only carry meaning; they are places where we make meaning. A kitchen is at once a mundane place for everyday activity and a liminal locus for possibility (see McCabe and Briody, 2018, on liminality in business). A kitchen is also a performance stage. In this sense, the baker is a magician who transforms everyday ingredients into a delightful treat (see Moeran and Malefyt, 2018, on anthropological approaches to contemporary magic). Mastery is demonstrated and the preparer's distinctive status, role, and identity are formed, exhibited, and lauded. A kitchen can be where fun happens, where families and friends gather to share tasks and bond as they prepare food they and their guests will consume. The nature of baking, as an enjoyable, elective activity, elevates the conviviality. A kitchen can be a place for discourse over food preparation and consumption that might not occur elsewhere. When a respondent recalled how she and her daughter had conversations while baking that they did not have at other times, the emotion in her voice was palpable. Any of these arenas could stimulate the invention of marketing opportunities for Duncan Hines.

Students were tasked with mining the anthropological theoretical domains to conjure up initiatives in any of several marketing areas, e.g., market segmentation, brand positioning, product design, user-experience (UX) opportunities, apps, pricing strategies, packaging, distribution channels. The students were also charged with considering the viability of their ideas based on criteria commonly considered in marketing practice. These include such questions as: Is your idea meaningful enough to passionate bakers? Is it distinctive to and ownable for Duncan Hines as a brand? Will it cut through the clutter of competitors' marketing? Does it reflect the current cultural moment? Are there barriers to executing the idea scientifically, legally, ethically, financially, or practically?

\section{Results of the Student Teamwork}

The students based their propositions on the findings of the ethnographies as well as the theoretical jumping off points (see Examples of Student Ideas). That outcome was not surprising. It illustrated that while anthropological constructs can stimulate intriguing marketing ideas, ethnography in itself is also a catalyst for marketing invention. The specific genesis of consumer insights from theory versus ethnography is not always clear. In practice, the power of the idea to generate brand growth is what matters most to marketers. Among some of the stronger student proposals were: an app with items to bake for lifecycle events, e.g., birthday, get well, anniversary, etc.; a baking product for children; a rewards system for children when they complete baking tasks; educational videos by established bakers to encourage other bakers and build on the feeling of mastering a skill; an advertising campaign that links baking with Duncan Hines with the spirit of giving gifts; adding gift packaging ideas to the Duncan Hines box; communications that depict the kitchen as a safe place for family discourse and bonding, e.g., brand packaging with pictures of a mother smiling in the background while her daughter mixes ingredients in a bowl and a selling line, "A Family That Bakes Together, Stays Together." Some of these proposals were inventive, and they demonstrate how effectively this exercise engaged students in the ethnographic case and the application of an anthropological sensibility to create potentially brand building ideas.

\section{Examples of Student Ideas ${ }^{12}$}

- Kitchen as a sacred place to form connections

- Baking as a family heirloom

- Kitchen is the heart of your home and Duncan Hines is at the centre of that

- Kitchen as a place to focus more on the group activity of baking the cake than the actual cake and including people who don't want to do real baking

- Packaging to incentivize different people doing different tasks

- Creating a place where people can feel safe and loved, to communicate freely with loved ones

- Modelling family values within the baking process; creativity, quality time with family and cleaning up the mess

- Modelling cultural rules and values: Baking across generations and inculcating values of teamwork in children, quality time/bonding within the family

- Instagram campaign where users could show themselves baking the product

- Baked goods specific to occasions, as greeting cards are, e.g., birthday, graduation, get well soon

- Make the kitchen a place for family to get together and have fun

- Multi-generational activity, baking passed down from grandparents to parents to children 
- Positioning Duncan Hines as a product that teaches soft skills like teamwork, task allocation, collaboration, which children will need in life

- Baking as an opportunity to engage and educate kids

- A baking product for kids; a rewards system for kids when they complete baking tasks

- Positioning Duncan Hines as a life saver for your family when you forget that last minute snack assignment/classmate's birthday

- Kitchen is the place for family to interact: a package that assigns the baking steps into different parts for each member of the family; purchasing the family package can be a new family memory

- Demonstrates mastery of skill and creativity; educational DIY videos by established bakers to inspire and build on the feeling of mastering a skill

- Baking items as a gift: run an ad campaign to link baking with the spirit of giving gifts, add gift packaging ideas to the box, give away gifts to charity for every item purchased

- Kitchen as a safe place for communication and family bonding, e.g., position Duncan Hines as a product that people come together over: "A Family That Bakes Together, Stays Together"; packaging with a picture of a mother smiling in the background while her daughter mixes ingredients in a bowl; packaging with conversation starters, knock-knock jokes, fun facts, etc. to facilitate conversation and bonding

- Promote Duncan Hines baking as an essential wellness activity, good for the mind, heart, and soul; a healthy soul activity (alongside meditation, yoga, etc.) with packaging featuring peaceful images

- Kids product stressing that Duncan Hines is simple and safe to bake

- Baking as a way of gifting a loved one with personalized, hand baked cakes as opposed to store bought

- Adding a community feeling by having a newsletter for bakers to join to build a supportive comfort network

- Creating memories and connections: offer in-person cooking classes in which participants can learn new skills, share recipes/ideas, and build community; app/website: create a social forum/platform on which users can post/share recipe ideas and build community virtually

- When people give to those who love cooking, give it with cooking equipment; could enable Duncan Hines to develop partnerships with kitchenware companies

- Duncan Hines as a family tradition used on holidays and passed down through generations

\section{Toward a Pedagogy for Consumer Anthropology}

Dedicated market research and anthropology professors who teach how cultural anthropology can be applied in marketing want to instruct their students on ways to think deeply about consumers. Because ethnographic method has tended to overshadow anthropological theory in market research practice and education, an opportunity to achieve weightier consumer understanding is missed. That curtails strategic novelty and brandbuilding. Consequently, work needs to be done to expand the teaching of consumer anthropology in business schools and other venues where consumer insight is sought and where applied market anthropology is in the curriculum. Most marketing students are more likely to become users of research than market research practitioners per se, e.g., they will use research findings provided by market research specialists to inform their marketing initiatives. For those students, a class session on consumer anthropology will raise their awareness and appreciation of its strengths. Future market researchers will gain an introduction to the discipline as a gateway to further reading and training. In either case, a fuller application of anthropology - beyond ethnography alone will help deliver a key goal of marketing education. As one student phrased it in a comment on the Columbia Business School market research course, "Putting theory into practice is what an MBA is about."

The classes described here had two functions: (1) To illustrate for marketing students how market research could benefit from both ethnographic method and anthropological theory and (2) to engage them experientially with anthropological theory to conceive market initiatives (see Thyroff, 2019, on experiential learning for market research education). For marketing students inclined toward quantitative market research and enamoured with big data, professors might find that qualitative research linked with theory presents a pedagogical challenge. However, in-class teamwork along the lines described here can help business students internalize the value of anthropological thinking.

Consumer anthropology enriches understanding and imparts uncommon insights. As with all qualitative research, marketing ideas generated through consumer anthropology should be optimized and assessed in quantitative research prior to launch into the marketplace. Before those steps can be taken, marketers need to 
Teaching Anthropology 2022, Vol. 11, No. 2, pp. 37- 47.

learn and appreciate what consumer anthropology can accomplish. A good place for that to begin is in the business school classroom.

\section{Notes}

${ }^{1}$ For some history on the application of anthropology in business, see Jordan (2019).

2 Anthropologists are less prone to separate ethnography from theory (Nader, 2011; for additional perspectives on ethnography and theory, see Cury and Bird, 2016; Ladner, 2014: 21-38; Morais, 2009; Wilson and Chaddha, 2010).

${ }^{3}$ Many anthropologists in business are reluctant to communicate their use of theory explicitly with practically minded clients and colleagues (Powell, 2021).

${ }^{4}$ In other realms of business school education, e.g., management, theory has more sway.

5 The author was the professor in the three class sessions. One class, at Columbia Business School, was a session in a course he teaches regularly. Two classes were at Cornell University SC Johnson Graduate School of Management where he was a guest lecturer. The total number of students was approximately 200.

${ }^{6}$ At the time this research was conducted, Duncan Hines (a brand marketed in the United States) was owned by Pinnacle Foods. It was subsequently purchased by Conagra Brands. The research and workshop were led by the author who was a Principal and co-owner of Weinman Schnee Morais, a market research firm. For a case on using ethnographic methods to inform Duncan Hines innovation, see Meyer et al., 2016.

7 The summary presentation of the research findings and workshop content allowed sufficient class time for the student exercise.

${ }^{8}$ Students in the author's business courses are given the following characterization of culture: Culture is rules, beliefs, values, and sentiments by which people navigate and make meaning in the world. It is ideas and actions, symbols and artifacts, verbal and non-verbal communication. Culture is learned, experienced, and shared, and manifested individually and societally. It is geo-specific and pan-human. It is ancient and of the moment, always changing.

9 Thick description, a term introduced to cultural anthropology by Geertz (1973), is a useful "handle" for students.

${ }^{10}$ These examples are based on real-world projects. Most have been published, and students interested in learning more about them were told that resources would be provided.

${ }^{11}$ Ethnography was the methodology requested by Duncan Hines executives. They were aware that the market research firm Principal who would lead the project was a consumer anthropologist.

12 These ideas were selected from a longer list and were edited lightly by the author.

\section{Disclosure statement:}

No potential conflict of interest was reported by the author.

\section{References}

Arnould, E. J. and Wallendorf, M. (1994) Market-oriented ethnography: Interpretation building and marketing strategy formulation. Journal of Marketing Research 31(3), 484-504.

Aucoin, P. (2017). Toward an anthropological understanding of space and place. Bruce B. Janz (Ed), Place, Space and Hermeneutics, pp 395-412. New York: Springer.

Baba, M. L. (2014). De-anthropologizing ethnography: A historical perspective on the commodification of ethnography as a business service. R.M. Denny and P. L. Sunderland (Eds), Handbook of Anthropology in Business, pp.43-68. Walnut Creek, LA: Left Coast Press.

Boyd, D. and Goldenberg, J. (2013). Inside the Box: A Proven System of Creativity for Breakthrough Results. New York: Simon and Shuster.

Csikszentmihalyi. M. (1990). Flow: The Psychology of Optimal Experience. New York: Harper and Row.

Cury, M. and Bird, D. (2016). Applying Theory to Applied Ethnography. 2016 Ethnographic Praxis in Industry Conference Proceedings, 201-216.

Gebhardt, G. (2015). Yes, Virginia, we "do" ethnography in business schools. EPIC Perspectives, March 3. https://www.epicpeople.org/yes-virginia-we-do-ethnography-in-business-schools/

Geertz, C. (1973). The Interpretation of Cultures. New York: Basic Books.

Granovetter, M. S. (1973). The strength of weak ties. American Journal of Sociology. 78(6):1360-1380. 
Teaching Anthropology 2022, Vol. 11, No. 2, pp. 37-47.

Hasbrouck, J. (2018). Ethnographic Thinking: From Method to Mindset. New York: Routledge.

Jordan, A.T. (2019). Business anthropology. Oxford Research Encyclopaedias. https://doi.org/10.1093/acrefore/9780190854584.013.4

Krawinkler, S.A. (2016). Teaching aspects of business anthropology. International Journal of Business Antbropology, 6(1), 95-108.

Ladner, Sam (2014). Practical Ethnography: A Guide to Doing Ethnography in The Private Sector. Walnut Creek, CA: Left Coast Press.

Malefyt, T. de Waal. (2003). Models, metaphors and client relations: The negotiated meanings of advertising. Malefyt, T. de Waal and Moeran, B., (Eds), Advertising Cultures, pp 139-163. New York: Berg.

Malefyt, T. de Waal. (2015). The senses in anthropological and marketing research: Investigating a consumerbrand ritual holistically. Journal of Business Anthropology, 4(1), 5-30.

Malefyt, T. de Waal and Morais, R.J. (2012). Advertising And Anthropology: Ethnographic Practice and Cultural Perspectives. Oxford: Berg.

Malhotra, N. K and Dash, S. (2017). Marketing Research: An Applied Orientation. 7th Edition. Noida, India: Pearson.

Maschio, T. (2015). Everyday things: an anthropologist's take on emotion and the sense of the sacred in consumer rituals. Journal of Business Antbropology, 4 (2), 342-351.

Mauss, M. (1990; Orig 1925) The Gift: The Form and Reason for Exchange in Archaic Societies. London: Routledge.

McCabe, M. (2014). Configuring family, kinship \& natural cosmology: Branding pet food. R.M. Denny and Sunderland, P. L. (Eds), Handbook of Anthropology in Business, pp 362-378. Walnut Creek, LA: Left Coast Press.

McCabe, M. and Briody, E. eds. (2016). Special Issue \#2: Liminality. Journal of Business Antbropology. Spring.

McCabe, M. and Denny, R. (2019). Anthropology in consumer research. Oxford Research Encyclopaedias. https://doi.org/10.1093/acrefore/9780190854584.013.9

McCabe, M., Malefyt, T. De Waal, and Fabri, A. (2017). Women, makeup, and authenticity: negotiating embodiment and discourses of beauty. Journal of Consumer Culture, 20(4), 656-677.

McCracken, G. (2016). Dark value: How to find hidden value in the digital economy. https://www.amazon.com/Dark-Value-hidden-digital-economy-ebook/dp/B01F6BBIVW

Meyer, M. H., Crane, F. G., and Lee, C. (2016). Connecting ethnography to the business of innovation. Business Horizons, 59, 600-711.

Moeran, B. and Malefyt, T de Waal, eds. (2018). Magical Capitalism: Enchantment, Spells, and Occult Practices in Contemporary Economies. London: Palgrave Macmillan.

Moisander, J., Närvänen, E., and Valtonen, A. (2020). Interpretive marketing research: Using ethnography in strategic market development. Penaloza, L., Visconti, L., and Ozcaglar-Toulouse, N., (Eds), Marketing Management: A Cultural Perspective. pp337-253. $2^{\text {nd }}$ edition. London: Routledge.

Morais, R. J. (2009). Business ethnography and the discipline of anthropology. Quirk's Marketing Research Review. February: 20, 22.

Morais, R. J. (2014). In pursuit of strategy: Anthropologists in advertising. Denny, R.M. and Sunderland, P. L., (Eds) Handbook of Anthropology in Business, pp 571-587. Left Coast Press. 
Teaching Anthropology 2022, Vol. 11, No. 2, pp. 37-47.

Morais, R. J. (2020). Inspiring brand positionings with mixed methods: A case of pet food. Journal of Business Anthropology 9(2), 251-27.

Morais, R.J. and Malefyt. T. de Waal. (2010). How anthropologists can succeed in business: Mediating multiple worlds of inquiry. International Journal of Business Antbropology 1(1), 45-56.

Nader, L. (2011). Ethnography as theory. HAU: Journal of Ethnographic Theory 1(1), 211-219.

Orta, A. (2019). Making Global MBAs: The Culture of Business and the Business of Culture. California Series in Public Anthropology. Oakland: University of California Press.

Osborn, A. F. (1957). Applied Imagination. New York: Scribner.

Powell, E. (2021). Fieldwork in a foreign culture: Business. Journal of Business Anthropology. 10(2), 368-385.

Roberts, J. M., and Sutton-Smith, B. (1962). Child training and game involvement. Ethnology. 1(2), 166-185.

Sahlins, M. (1972). Stone Age Economics. London: Routledge.

Sherry, Jr., J.F. (1983). Gift giving in anthropological perspective. Journal of Consumer Research. 10(2), 157-168.

Stewart, A. (2014). Too rare to be a token: An anthropologist in a management department. Journal Of Business Antbropology 3(2), 140-158.

Sunderland, P. L. and Denny, R.M. (2003). Psychology vs. anthropology: Where is culture in marketplace ethnography? T. de Waal Malefyt, T. de Waal and Moeran, B. (Eds), Advertising Cultures, pp 187-202. Oxford: Berg.

Sunderland, P. L. and Denny, R.M. (2007). Doing Anthropology in Consumer Research. Walnut Creek, CA: Left Coast Press.

Sunderland, P. L. (2013). The cry for more theory.” Jordan, B. (Ed), Advancing Ethnography in Corporate Environments: Challenges and Emerging Opportunities, 122-35. Walnut Creek, CA: Left Coast Press.

Tett. G. (2021) Anthro-Vision:_A New Way to See in Business and Life. New York: Avid Reader Press.

Tian, R. G. and Walle, A. H. (2008). Anthropology and business education: Practitioner applications for qualitative method. International Journal of Management Education. 7 (2), 59-67.

Thyroff. A. (2019). Teaching qualitative marketing research: An experiential approach. Marketing Education Review, 29(1), 75-87.

Wilson, W. J. and Chaddha, A. (2010). The role of theory in ethnographic research. Ethnography,10(4), 549-564. 